\title{
LOW COST LEVEL II NEWBORN CARE SERVICE: EXPERIENCE OF KATHMANDU MEDICAL COLLEGE TEACHING HOSPITAL
}

\author{
Manandhar D S*, Manandhar K
}

\section{ABSTRACT}

Newborn infants require special care when they become sick. Majority of the newborn require only feeding, warmth and loving care by the mothers. Nearly $15-20 \%$ of newborns become sick requiring care in hospital. Most of these babies can be managed using low cost locally made equipment which makes newborn care affordable. This is a prospective study of 201 sick newborns looked after in the Special Care Baby Unit (SCBU) of Kathmandu Medical College Teaching Hospital (KMCTH) using locally made low cost equipment. In the period of 28 months from $2^{\text {nd }}$ July, 2001 to 17th Oct. 2003, 882 babies were delivered at Kathmandu Medical College Teaching Hospital (KMCTH). 859 were live births. Out of 859 live births, 173 (20.1\%) were admitted in the special care baby unit (SCBU). SCBU of this hospital also admitted 28 babies born outside the hospital. The main causes of admission in SCBU were low birth weight $(37.3 \%)$, neonatal jaundice (18.9\%), birth asphyxia (6.9\%), septicaemia (2.4\%) and out of 201 babies admitted in SCBU, 89\% were discharged in good condition, $3.9 \%$ of the babies left against medical advice, 2 babies (one with congenital hydronephrosis and another with congenital hypertrophic pyloric stenosis) were transferred to Kanti Children Hospital for surgery and 11 babies (5.4\%) expired. The main causes of neonatal deaths were extreme prematurity (70\%), septicaemia (23\%), birth asphyxia (15.3\%) and congenital anomalies (7.6\%). The perinatal mortality rate (PMR) and neonatal mortality rate (NMR) during this period were 26.4/1000 births and 15.1/1000 live births respectively. In SCBU, locally made low cost equipment (Resuscitaire, Warm cot, Phototherapy and Oxygen hood designed by Prof D.S. Manandhar) are being used in the manangement of sick babies, since the unit was started on $2^{\text {nd }} \mathrm{July,} \mathrm{2001}$. Babies with birth weight as low as 1020 gms and gestation as low as 28 weeks have survived in this unit. This unit has shown that Level II care could be provided with simple and low cost equipment and results are quite satisfactory. Good antenatal care, good care during delivery including use of partogram and care during postnatal period have helped to make this result good. Expansion of such facilities in district and bigger hospitals in the country are not only affordable but also will have great impact in saving many lives. This will have a major impact in reducing the present high IMR and NMR of the country.

Key Words: Care of sick neonates, low cost locally made equipment, common neonatal problems, special care baby unit, and level II care.

\section{INTRODUCTION}

Newborn infants require special care when they become sick. They have limited capability of maintaining temperature and are prone to get infections very easily. Deaths within four weeks of birth (neonatal deaths) account for $60 \%$ of infant mortality ${ }^{1}$.
Though there has been significant reduction in IMR in last 30 years due to various public health programmes, reduction of infants death has been seen only in postneonatal period. Nearly 831,000 babies are born every year in the country ${ }^{2}$ and 10$15 \%$ develop problems requiring hospital care ${ }^{3}$. About 1-3\% will require intensive care. Facilities for care of sick newborns

* Kathmandu Medical College Teaching Hospital, Sinamangal, Kathmandu, Nepal.

Address for correspondence : Prof. D. S. Manandhar

Kathmandu Medical College Teaching Hospital, Sinamangal, Kathmandu

Email: dsm@healthnet.org.np 
are very limited in Nepal and outside Kathmandu, it is available in few hospitals only. Lack of knowledge on the care of the newborns and the feeling that newborn care requires costly and sophisticated equipment have inhibited expansion of even basic newborn care facilities in the district hospitals. The special care baby unit (SCBU) of Kathmandu Medical College Teaching Hospital (KMCTH) is using low cost locally made equipment in the care of sick newborns. Experience of using such equipment in the care of sick newborns is presented here.

\section{METHODOLOGY}

Prospective study of babies admitted in the SCBU in the period of 28 months ( $2^{\text {nd }}$ July 2001 to $17^{\text {th }}$ Oct. 2003). Locally made low cost equipment - DSM Resuscitaire (fig.1) and DSM Warm Cot (fig.2) were used to keep the baby warm. DSM Phototherapy Unit (fig.3) was used to treat hyperbilirubinaemia. Locally made oxygen hood is used to provide oxygen. Autoclaved newspapers (Fig.4) were used to wipe the hands after washing. In KMCTH delivery service was started from 29th May, 2001 and SCBU was started on 2nd July, 2001. In KMCTH, all deliveries are attended by a medical officer from the department of Paediatrics and $2^{\text {nd }}$ on call is also available at delivery whenever needed. All

Fig. 1

Fig. 2

\section{Fig. 2 : DSM Warm Cot}

babies are examined within 24 hours in postnatal ward and all babies are examined everyday and before discharge. Babies requiring observation and special care are transferred to SCBU. All the newborns are being followed up in the well baby clinic on Tuesdays. Those with special problems are advised to come earlier.

There is a "Resuscitation corner" in the Labour Room and Special Care baby Unit. Resuscitation corner in labour room is supplied with a locally made resucitaire, suction machine, oxygen, resuscitation equipment (self-inflating resuscitation bag, laryngoscope, ET tubes), essential drugs and disposables.

The Special Care Baby Unit (SCBU) has 10 beds. It has two rooms. The inner room with monitors is for the care of very sick babies and the outer room for less sick babies not requiring monitors. A separate room nearby is kept for the mothers for easy access and promotion of exclusive breastfeeding. Equipment used are designed by Prof D.S.Manandhar and are locally made low cost equipment: "DSM" Resuscitaire, "DSM" Warm cot, "DSM" Phototherapy Unit and of Oxygen hood. Those requiring warmth are initially kept in a resuscitaire then transferred to a warm cot. Room temperature is maintained at $28^{\circ} \mathrm{C}$ by using air conditioners and fan heaters. Phototherapy 
Fig. 3

\section{Fig. 3 : DSM Phototherapy Unit}

is started whenever serum bilirubin goes above $15 \mathrm{mg} / \mathrm{dl}$. Oxygen is administered by oxygen hood when it is required. 12 nurses, 6 medical officers, supervised by lecturers, senior registrar and consultants look after sick newborns and other general pediatrics patients.

\section{RESULTS}

In the period of 28 months, 882 babies were delivered in KMCTH. Out of 882 babies delivered in KMCTH, 859 were live births. 3 babies died before admission in the SCBU. A total 201 babies were admitted in SCBU which included 28 babies born outside the hospital. Out of 859 live births in KMCTH, 173 babies (20.1\%) were admitted in SCBU. The main causes of admission in SCBU were low birth weight, neonatal jaundice, birth asphyxia, septicemia, and others. The tables given below give data on 201 newborns admitted during the study period. Among the admitted babies $44.2 \%$ were of low birth weight and $8.45 \%$ were of very low birth weight as shown in Table I. Most low birth weight infants were therefore in the weight group of 1500-2499 gms. Majority of the babies $(70.6 \%)$ were also term infants, with less than $10 \%$ below 32 weeks gestation. Among low birth weight babies 53\% were small for dates and $47 \%$ were preterm.

\section{Fig. 4}

\section{Fig. 4 : DSM Autoclaved Newspaper}

Among the admitted babies $61.1 \%$ were male and $38.3 \%$ were female. Regarding causes of admission, most admission were for low birth weight (37.3\%), 18.9\% for neonatal jaundice, $6.9 \%$ for birth asphyxia, $5.9 \%$ for respiratory problems, $2.4 \%$ for septicaemia and $28.3 \%$ for miscellaneous causes which include poor feeding, vomiting, fever, hypothermia, meconium stained liquor, etc. The average duration of stay was 1-3 days $(46.7 \%)$. Of the babies admitted from outside the hospital, $50 \%$ were born at Prasuti Griha, 25\% at home, 14\% at Patan Hospital, $7 \%$ at Nursing homes and $4 \%$ outside Kathmandu. The commonest cause for admission among the babies born outside the hospital was neonatal jaundice.

Out of 201 babies $89 \%$ were discharged in good condition, $4 \%$ left against medical advice, $5 \%$ expired and $1 \%$ transferred to Kanti Children Hospital. The main causes of death of the babies were extreme prematurity (53.8\%), septicaemia (23\%), birth asphyxia (15.2\%) and congenital anomalies (7.6\%). The survival of babies by birth weight and gestation is shown in table V and VI. Babies with birth weight below 1000 gms did not survive. The survival of babies with birth weight between 1000 gms to $1499 \mathrm{gm}$ was $67 \%$. The survival of babies with birth weight between 1500 gms to 1999 gms, between 2000 gms to 2499 gms and above 2500 gms were $86 \%, 98 \%$ and $99 \%$ respectively. By gestation also, those with less than 28 weeks of gestation did not survive. $80 \%$ of babies with gestation between 28 weeks to 31 weeks survived. $89 \%$ of babies with gestation 32 weeks to 36 weeks survived and $99.5 \%$ of babies with gestation above 37 weeks survived. Among the admitted babies, 4 of them were kept on a ventilator but they did not survive. 3 babies were admitted for hyaline membrane disease and one baby for multiple congenital anomalies.

The perinatal mortality rate (PMR), extended perinatal mortality rate (EPMR), neonatal mortality rate (NMR) and NMR excluding $<1 \mathrm{~kg}$ during this period were $26.4 / 100$ births 39/1000 births, 15.1/1000 live births and 10.5/1000 live births respectively, which are quite satisfactory. 
Table I : According to birth weight of the babies born at KMCTH and admitted in the SCBU

\begin{tabular}{lc|c|c|c}
\hline \multicolumn{1}{c}{ Birth weight } & $\begin{array}{c}\text { Delivered at KMCTH } \\
(\mathbf{2 8} \text { months })\end{array}$ & \% & $\begin{array}{c}\text { Total admission } \\
(\mathbf{2 8} \text { months })\end{array}$ & \% \\
\hline$<1 \mathrm{~kg}$ & 12 & 1.3 & 4 & 2 \\
\hline $1-<1.5 \mathrm{~kg}$ & 12 & 1.3 & 13 & 6.5 \\
\hline $1.5-<2 \mathrm{~kg}$ & 12 & 1.3 & 27 & 13.5 \\
\hline $2-<2.5 \mathrm{~kg}$ & 55 & 7 & 45 & 22 \\
\hline $2.5 \mathrm{~kg}$ and above & 791 & 90 & 112 & 56 \\
\hline Total & $\mathbf{8 8 2}$ & $\mathbf{1 0 0}$ & $\mathbf{2 0 1}$ & $\mathbf{1 0 0}$ \\
\hline
\end{tabular}

Table II : According to maturity of the babies born at KMCTH and admitted in the SCBU

\begin{tabular}{c|cc}
\hline \multicolumn{1}{c|}{ Maturity } & Total (28 months) & \% \\
\hline$<28$ weeks & 0 & 0 \\
\hline $28-<32$ weeks & 14 & 7 \\
\hline $32-36$ weeks & 45 & 71 \\
\hline 37 weeks and above & 142 & $\mathbf{1 0 0}$
\end{tabular}

Table III : According to cause of admission of the babies admitted in the SCBU

\begin{tabular}{l|cc}
\hline \multicolumn{1}{c|}{ Cause of Admission } & Total (28 months) & \% \\
\hline Low Birth Weight & 75 & 37 \\
\hline Neonatal Jaundice & 38 & 19 \\
\hline Birth Asphyxia & 14 & 7 \\
\hline Respiratory Problems & 12 & 6 \\
Septicemia & 5 & 3 \\
Miscellaneous Causes & 57 & 28 \\
$\quad$ Total & $\mathbf{2 0 1}$ & $\mathbf{1 0 0}$ \\
\hline
\end{tabular}

Table IV : According to the cause of total newborn deaths at KMCTH

\begin{tabular}{l|cc}
\hline \multicolumn{1}{c|}{ Cause of Death } & Total (28 months) & \% \\
\hline Extreme Prematurity & 7 & 54 \\
\hline Septicaemia & 3 & 23 \\
\hline Birth asphyxia & 2 & 15 \\
\hline Congenital anomalies & 1 & 8 \\
\hline \multicolumn{1}{c|}{ Total } & $\mathbf{1 3}$ & $\mathbf{1 0 0}$ \\
\hline
\end{tabular}

Table V : Survival of babies born at KMCTH by birth weight

\begin{tabular}{lc|c|c}
\hline \multicolumn{1}{c|}{ Birth weight } & No. of live births & No. of babies survived & \% \\
\hline$<1 \mathrm{~kg}$ & 4 & 0 & 0 \\
\hline $1-<1.5 \mathrm{~kg}$ & 9 & 6 & 67 \\
\hline $1.5-<2 \mathrm{~kg}$ & 7 & 6 & 85 \\
$2-<2.5 \mathrm{~kg}$ & 54 & 53 & 98 \\
$2.5 \mathrm{~kg}$ and above & $\mathbf{7 8 5}$ & $\mathbf{7 8 0}$ & $\mathbf{9 9}$ \\
\hline
\end{tabular}

Table VI : Survival of babies born at KMCTH by gestation

\begin{tabular}{lc|cc}
\hline \multicolumn{1}{c|}{ Maturity } & No. of live births & No. of babies survived & \% \\
\hline$<28$ weeks & 2 & 0 & 0 \\
\hline 28-<32 weeks & 10 & 8 & 80 \\
\hline $32-36$ weeks & 45 & 40 & 88 \\
37 weeks and above & 802 & 798 & 99
\end{tabular}




\section{DISCUSSION}

In our special care baby unit, we have managed 201 babies with different problems. Babies with birth weight of 1020 gms and gestational age as low as 28 weeks have survived. The problems ranging from respiratory distress, birth asphyxia, septicemia and others were managed with the use of low cost locally made equipment and this service was provided at fairly low cost which is affordable by majority of the people. Majority of neonatal deaths in KMCTH was due to extreme prematurity, for whom intensive care with ventilator support is required. NMR of this hospital is $15.1 / 1000$ live births which is quite low in comparison to national NMR of 38.4/1000 live births. Excluding the babies weighing $<1 \mathrm{~kg}$, NMR comes to $10.3 /$ 1000 live births. Facilities available in SCBU are affordable, as locally made low cost equipment are used in this unit. Equipment for care of sick newborn constitutes a large proportion of cost of a neonatal unit.

The equipment are comparatively very cheap, easy to operate and maintain. Any local electrician could repair and maintain it. The nurses have found these equipment to be very user friendly and there was no problem in using them.

There is a misconception that newborn care depends upon interventions, which are too costly or technological for high coverage in poor countries. This attitude has been aggravated by the exposure of professionals to neonatal intensive care units. Majority of newborn care requires only minimal care i.e. feeding, warmth and cleanliness, which are generally provided by the mother. But, in fact, mothers, health professionals and policymakers all seems to lack education about simple, low cost principles of newborn care laid down by the French obstetrician Pierre Budin in his classic work "The Nursling". ${ }^{4}$ Nearly $15 \%$ newborn babies develop problems requiring hospital care. ${ }^{4}$ Only $1-3 \%$ will require intensive care. In Nepal common neonatal problems requiring care in hospital are- birth asphyxia, low birth weight, infection, jaundice, feeding problems and respiratory distress. Most of these problems could be managed using low cost locally made equipment. For proper management of birth asphyxia, there should be a resuscitation corner in the labour room with essential drugs and equipment. Most of the babies require thermal control for which the incubators used are very costly in comparison to the locally made warm cot and resucitaire. In our experience, we found that temperature of the babies has been well maintained throughout the hospital stay by using locally made resuscitaire and warm cot. Neonatal hyperbilirubinaemia was managed by using locally made phototherapy unit.

Most infants are born at home, so mother is the prime care provider during newborn period. With increasing urbanization, significant proportions of infants in urban areas are born in hospital. In Kathmandu valley, it has been estimated that nearly $65 \%$ births occur in the hospitals..$^{5}$ Neonatal care services outside Kathmandu is very limited and is available in few hospitals only. The main obstacle for expanding neonatal care services in district, zonal and regional hospitals has been the feeling that imported costly and sophisticated equipments like incubators, ventilators and highly skilled personnel are required. The present study has shown that most of the sick newborns could be managed using locally made low cost equipment. Such equipment are being used in the care of the newborns in eight district hospitals where Safer Motherhood Programme has been implemented by Nepal Safer Motherhood Programme.

\section{CONCLUSION}

Nearly $15 \%$ of newborn babies develop problems requiring care in a hospital. Most of these problems could be managed by using locally made low cost equipment as has been shown by our experience. Locally made low cost equipment are affordable and easy to operate and maintain. Providing such facilities in district hospitals will help in reducing the present high neonatal mortality which constitutes over $60 \%$ of infant mortality rate of the country.

\section{ACKNOWLEDGEMENT}

Thanks are due to Mother and Infant Research Activities (MIRA) for the support provided in this study.

\section{REFERENCES}

1 Mni stry of Heal th (Nepal), New ERA ORC MACRO Nepal denographi c and heal th survey 2001. Cal verton, Maryl and, Fannl y Heal th D vi si on, Mni stry of Heal th; New PA: ORC MACRO 2002.

$2 \mathrm{~W} \oplus \mathrm{F}$ The State of the Vorl d"s Children Oford Uriversity Press (1995).

3 Nenandher DS Sped al care of nevborn at the d strict hospital, in i nor ovi ing Neuborn I nf ant Heal th in Devel opi ng Cantries. Eds. A costel I o and D Manandhar, I nperi al Col I ege Press 2000.

4 Bud $\mathrm{n}$ P. The Nusl ing. The feed ing and hygi ene of prenature and ful termi ifarts. Transl ated by Mal oney W. The Caxton Publ i shi ng Conpany (1907) London.

5 Manandhar DS, Bol amA, Strestha P, Manandhar B, Mall I K Strestha LN Elis M and Costel Io AMde L "Nerrity care uti l i zati on in Katmandu val l ey: A comnani ty based study," J ournal of Nepal Nedical Associ ati on 35(1997): 122-129.

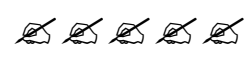

